\title{
Chemoembolization in Metastatic Liver Neoplasms: KADR Experience
}

\author{
MAHMOUD S. AL-AHWAL, FRCP(C)*, MOHAMMAD M. RAWAS, FRCR(C)**, \\ HISHAM O. AKBAR. FRCP(C)* \\ Department of Medicine* and DepartmentofRadiology**, Faculty of Medicine \& \\ Allied Sciences, King Abdulazi: University, Jeddah, Saudi Arabia
}

\begin{abstract}
Objective: To assess the results of chemoembolization in this pilot study for patients with unresectable metastatic liver neoplasms.

Methods: Patients with unresectable liver metastases secondary to different primary tumors who did not have decompesated liver disease underwent selective intra-arterial chemotherapy consisting of 5-flourouracil, adriamycin and cisplatin followed by embolization of the feeding artery using Poly Vinyl Alcohol Particles (PVAP). Courses of treatment were given every four to six weeks for a minimum of three courses.
\end{abstract}

Results: Eight patients with bilateral multiple or diffuse liver metastasis underwent chemoembolization. Five out of eight patients had good palliation of symptoms and improvement in their quality of life. Their average duration of palliation was 7.2 months. Median survival for all patients was seven months. Seven patients died within the first year from a diagnosis of liver metastasis. The last patient with carcinoid syndrome is still alive 36 months after diagnosis.

Conclusion: Selective intra-arterial chemotherapy followed by embolization in this pilot study with unresectable liver metastases gives palliation of symptoms and improvement in the quality of life for almost half of our patients but for a short duration. Patients with neuroendocrine tumors may have longer duration of palliation and survival. Further randomized trials with a higher number of patients would be worthwhile pursuing.

Keywords: Liver, Neoplasm. Arteries, Chemoembolization.

\section{Introduction}

Chemoembolization is a well established procedure in liver neoplasms. Most common indication is palliative management of unresectable tumors, both primary and metasta-

Correspondence \& reprint requests to: Dr. Mahmoud AI-Ahwal, P.O. Box 6615, Jeddah 21452, Saudi Arabia. Accepted for publication: 08 March J998. Received: 06 January 1998. 
tic [1.2]. It is mainly used in reducing tumor burden, in pain control and hormoneproducing tumors, neuroendocrine, and alleviation of symptoms caused by hypersecrection. Hepatic intra-arterial injection of anti-tumor agents is performed to increase the local concentration of drugs and reduce systemic side effects [3]. Intra-arterial embolization causes ischemic necrosis of the tumor [4], which leads to tumor size reduction, palliation of symptoms, and may prolong survival[5.6].

To our knowledge, selective intra-arterial chemoembolization for primary and metastatic liver tumors is a novel method not commonly used in Saudi Arabia and treated with conventional chemotherapy protocols. Our aim from this pilot study is to assess the results of intra-arterial chemotherapy followed by embolization to patients with unresectable metastatic liver tumors in our population.

\section{Materials and Methods}

Consequative patients who met the entry criteria and who agreed to participate were included in this study. Inclusion criteria were: performance status (Karnofsky $>600 / 0$ ), ageless than 70 years, unilobar or bilobar tumor, pain secondary to tumor spread in the liver, and normal liver function tests except alkaline phosphatase and gama glutamic transferase. Patients were excluded if they had a surgically resectable tumor, had decomensated hepatic disease, portal vein thrombosis, or had contraindication to treatment with 5-fluorouracil (5-FU), adriamycin, or cisplatin.

Chemoembolization: After admission to the hospital, patients underwent intra; arterial catheter insertion through the femoral artery by the radiologist. Arterial system mapping was obtained and portography was carried out in all patients. Hepatic artery catheterization was followed. The tip of the catheter was advanced to be distal to the gastroduodenal artery or one of its branches. Either right or left branches of the hepatic artery wàs then catheteried. The catheter was later connected to an arterial pumb, then patients were transferred to the medical ward. Chemotherapy consisting of "5flourouracil $(1000 \mathrm{mg} / \mathrm{rrr}$ '), adriamycin $(50 \mathrm{mg} / \mathrm{rrr}$ '), and cisplatin $(50 \mathrm{mg} / \mathrm{rrr})$ " were all infused intra-arterially and sequentially each over two to four hours. Within 24 hours, patients underwent embolization and complete occlusion of the arterial vascular bed of the tumor by the radiologist using PVAP of 700 micron in size, followed by removal of the catheter. Patients went home 24-48 hours later. The procedure was repeated every four te six weeks for a maximum of three cycles.

Follow-up: Liver function tests and computed tomgraphic scans were obtained as a baseline and before each cycle. Palliation of symptoms (pain, nausea, vomiting, or any other symptoms) were all assessed before each cycle of chemoembolization by using a Visual Analogue Scale. Complications were documented for all patients. Data were collected analyzed.

$$
\text { Results }
$$

Patient characteristics: The trial began in March 1994. Eight patients enrolled in this trial until March 1997. Characteristics of these patients and their treatment outcome are summarized in (Table I). 
TABLE 1. Patient characteristics and their treatment outcome after Transarterial Chemoembolization (TACE).

\begin{tabular}{|c|c|c|c|c|c|c|c|c|c|c|c|}
\hline No. & \multirow{2}{*}{ Age } & Sex & \multicolumn{4}{|c|}{ Tumor } & TACE & T. Size \\
(No.) & Reduction & $\begin{array}{c}\text { Palliation } \\
\text { of } \\
\text { Symptoms }\end{array}$ & $\begin{array}{c}\text { Duration } \\
\text { of } \\
\text { Palliation } \\
\text { (Months) }\end{array}$ & Months & Status \\
\hline 1. & 55 & F & Colon & Multiple & II & 2 & $400 / 0$ & Yes & 6 & 12 & Dead \\
\hline 2. & 70 & M & NPC & Diffuse & II & 2 & $20 \%$ & Yes & 3 & 6 & Dead \\
\hline 3. & 40 & F & Breast & Diffuse & III & 1 & $10 \%$ & No & 0 & 3 & Dead \\
\hline 4. & 60 & F & Esophagu & Diffuse & II & I & $20 \%$ & Yes & 4 & 10 & Dead \\
\hline 5. & 65 & M & T.C.C. & Multiple & III & I & $5 \%$ & No & 0 & I & Dead \\
\hline 6. & 55 & F & Colon & Diffuse & II & I & $20 \%$ & No & 0 & 6 & Deads \\
\hline 7. & 52 & M & Colon & Multiple & II & 1 & $30 \%$ & Yes & 3 & 8 & Dead \\
\hline 8. & 50 & M & Carcinoid & Multiple & ] & 3 & $50 \%$ & Yes & 20 & 36 & Alive \\
\hline
\end{tabular}

NPC: Nasopharyngeal

TCC: Transitional Cell Carcinoma

Male to female ratio is $\mathrm{I}: 1$. Mean age is 55.9 years (40-70). The original primary tumor's were different (three colon, one breast, one transitional cell carcinoma of the urinary bladder, one esophagus, one nasopharyngeal carcinoma, and one carcinoid syndrome). Five patients had two cycles and one patient had three cycles. This was either because of death or a worsening of their liver function tests. All patients were not suitable for surgical resection.

Treatment Outcome: During the observation period (March 1994 - March 1997), response to treatment was assessed before each" cycle of TACE and during regular followup in the outpatient department. Regarding changes in tumor size, all patients had reduction in tumor burden of $50 \%$ or less $(10-50 \%)$. Five out of eight patients had palliation of their symptoms (pain control, nausea, vomiting, and hot flushes for the patient with carcinoid syndrome). The duration of palliation of their symptoms were short, ranging from three to 20 months (mean 7.2 months).

Survival: Seven out of eight patients died. The cause of death in all patients was tumor progression. The patient with the carcinoid syndrome (patient No.8) is still alive with minimal bouts of hot flushes which is well controlled by Sandostatin. The overall survival varies between one to 36 months with a median survival of seven months.

Complications: Among the eight patients, seven developed abdominal pain which was mild and lasted for one to two days; vomiting in six patients; and a low-grade fever in four patients. Temporary elevation.of liver enzymes occurred in seven out of eight patients which lasted for three to ten days followed by a rapid decline and normalization of liver function tests. One patient died within the first month of treatment from sepsis and renal failure. 


\section{Discussion}

Hepatic metastasis represents a common site of dissemination for a number of primary malignancies related in part to the dual blood supply, large blood flow, and receptive environment of the hepatic parenchyma. Liver metastasis are commonly seen in colorectal, gastric, breast, malignant melanoma, and neuroendocrine tumors. Hepatic resection of metastatic disease is commonly used to treat liver metastasis from colorectal cancer. For patients with multiple metastasis or those unable to undergo resection, other options are available like regional chemotherapy, embolization, or chemoembolization. Hepatic tumors obtain most of their blood supply from the hepatic artery, where as normal hepatocytes derive their blood supply from the portal circulation and the hepatic artery[7].

Recently, TAE has been performed successfully to treat patients with unresectable HCC with improvement in survival compared to arterial chemotherapy' alone or in patients who do not undergo treatment[5]. Various TAE methods have been used in the treatment of unresectable HCC. A combination of TAE with gelatin sponge, iodized oil and anti-cancer agents is now one of the most common techniques used in the treatment of liver neoplasms in many hospitals and medical centers in Japan[8,9]. Intra-arterial chemotherapy, with or without hepatic artery ligation or embolization, has been used to treat metastatic liver neoplasms with good results[1O, II].

In our pilot study, we elected to use hepatic intra-arterial infusion of effective chemotherapeutic agents slowly (two to four hours each) to increase the local concentration of drugs and reduce systemic side effects[3]. Embolization of the tumor blood supply was performed after completion of intra-arterial chemotherapy infusion using PVAP. Our preliminary results from this study revealed a $10-50 \%$ decrease in tumor size and five out of eight patients had palliation of symptoms within the' first month of treatment (Table I). The reduction in tumor burden and survival noted in our study is less impressive than other studies reported in the literature, using chemotherapy infusion through hepatic artery and or hepatic artery'ligation for liver metastasis secondary to colon cancer[10-12]. Didolkar et a/[IO] reported a 97\% response rate with a median survival of 23 months compared to a 62.50/0 response rate with a median survival of seven months in our study--seven out of eight patients (87.50/0) in our study of only 470/0 [10]. This difference may explain the poor results in our study of response rate, palliation of symptoms, and survival. The results of palliation are worthwhile, though short-lived. Our patient with carcinoid syndrome (patient No.8) had a significant reduction in tumor burden, palliation of symptoms for a long duration (20 months), and prolongation of survival (36 months). Chemoembolization is an effective palliative method in the management of metastatic neuroendocrine tumors to the liver. In 1993 Stokes and associates' 13] have obtained a 1000/0 symptom palliation rate with a 900/0 reduction of hormone levels and an 840/0 reduction in tumor burden in their study. The excellent response for metastatic carcinoid tumor is very encouraging which makes it worthwhile to pursue in the future for neuroendocrine tumors.

Notable success has been also achieved with embolization of ocular melanomas to the liver[2]. Other liver metastases, such as from the breast, lung, kidney, bladder, and- 
pancreas, and gastrointestinal sarcomas, have been treated with embolization. The series are small, however, so any statement on survival is premature.

The complications noted in our study in seven out of eight patients are similar to other series reported in the literature[14]. The most common complications postembolization are: pain, fever, nausea, and vomiting.

In conclusion, preliminary results from our pilot study showed that intra-arterial chemotherapy followed by embolization of tumor blood supply (TACE) is a novel approach for the treatment of liver metastasis which is prevalent in Saudi Arabia in palliation of symptoms and improvement in the quality of life but for a short duration. Perhaps other chemotherapy drugs could be utilized. Further randomized studies in comparison to conventional systemic chemotherapy, which is currently used in the majority of oncology centers, would be worthwhile pursing in a higher number of patients to show any advantage.

\section{References}

[1] Yamada R, Sato M, Kawabata M. Hepatic artery embolization in 120 patients with unresectable hepatomas. Raqiology 1993; 148: 397-401.

[2] Bedikian A, Legha SS, Mavligit G, Carrasco CH, Khorana S, Plager C, Papadopoulos N, Benjamin RS. Treatment of uveal melanoma metastatic to the liver: a review of the M.D. Anderson Cancer Center experience and prognostic factors. Cancer 1995: 76(9): 1665-1670.

[3] Ensminger WD, Gyves JW. Regional cancer chemotherapy. Cancer Treat Rep 1984;68: 101-115.

[4] Bruix J, CastelIs A, Montanya X, Calvet X, Bru C, Ayuso C, Jover L, Garcia L, Vilana R, Boix L. Phase II study of transarterial embolization in European patients with hepatocellular carcinoma: need for controlled trials. Hepatology 1994;20(3): 643-650.

[5] Hatanaka Y, Yamashita Y, Takahashi M, Koga Y, Saito R, Nakashima K, Urata J, Miyao M. Unresectable hepatocellular carcinoma: analysis of prognostic factors in transcatheter management. Radiology 1995: 195(3): 747-752.

[61 Bronowicki JP, Vetter D, Dumas F, Boudjema K, Bader R, Weiss AM, Wenger JJ, Boissel P, Bigard MA, DofToel M. Transcatheter oily chemoembolization for hepatocellular carcinoma. A 4-year study of 127 French patients. Cancer 1994: 74(1): 16-24.

[7] Sigurdson ER, Ridge JA, Kemeny N, Daly JM. Tumor and liver drug uptake following hepatic artery and portal vein infusion. J CUn Oncol 1987;5(11): 1836-1840.

[8] Nakamura H, Hashimoto T, Oi H, Sawada S. Transcatheter oily chemoembolization of hepatocellular carcimoma. Radiology 1989; 170: 783-786.

[9] Sasaki Y, Imaoka S, Kasugai H, Fujita M, Kawamoto S, Ishiguro S, Kojima j, Ishikawa O, Ohigashi H, Furukawa H. A new approach to chemoembolization therapy for hepatoma using ethiodized oil, cisplatin, and gelatin sponge. Cancer 1987;60(6): 1194-1203.

[10] Didolkar MS, Elias EG, Whitley NO, Keramati B, Jackson AJ, Hebel RJ, jordan TE. Unresectable hepatic metastases from carcinoma of the colon and rectum. Surg Gynecol Obstet 1985: 160(5): 429-436.

[II] Tada A, Ogawa M, Inagaki j, Horikoshi N, Inoue K, Yamazaki H, Nakamura T, Ueno K, Mukaiyama T, Ito Y. [Arterial infusion of combination chemotherapy consisting of adriamycin and mitomycin-C for liver metastases of breast cancer.] Gan To Kagaku Ryoho 1986: 13(1): 70-74.

[12] Ramming KP, Sparks FC, Eilber FR, Holmes EC, Morton DL. Hepatic artery ligation and 5-tluorouracil infusion for metastatic colon carcinoma and primary hepatoma. Am J Surg 1976; 132(2): 236-242.

[13] Stokes KR, Stuart KE, Clouse ME. Hepaticarterial chemoernbolization for metastatic neuroendocrine tumors. J Vasc lnterv Radio11993; 4: 341-345.

[14] Groupe d Etude et de Traitement du Carcinome Hepatocellulaire. A comparison of lipiodol chernoembolization and conservative treatment for unresectable hepatocellular carcinoma. NEJM 1995; 332 (19): 1256-1261. 


\title{
لمعالجــة لكيميائية لسرطـاتة لكبـدا لثانوذتخ لأورام.أوليـة

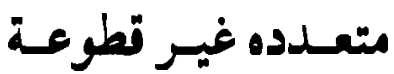

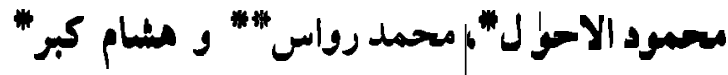

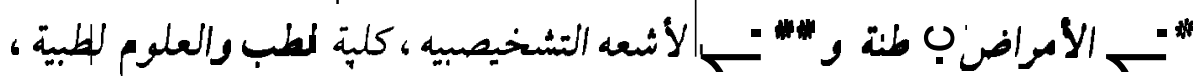

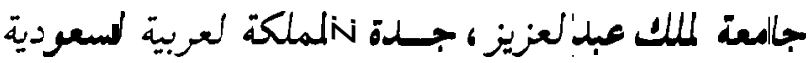

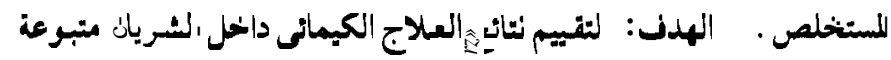

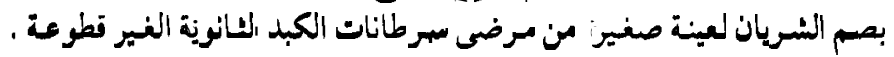

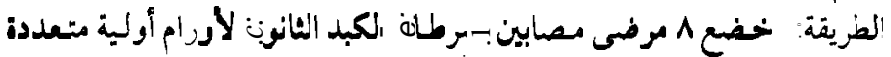

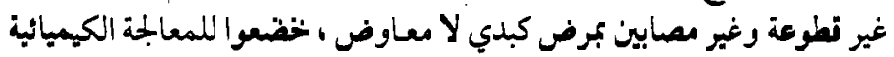

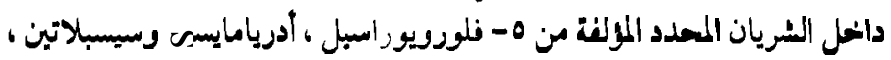

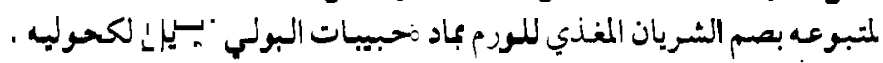

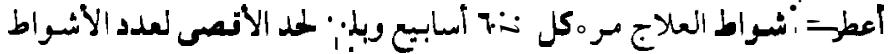

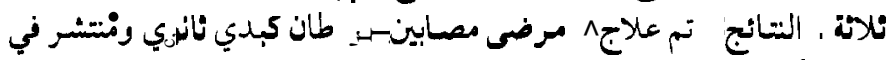

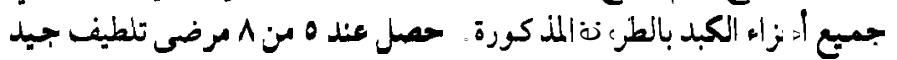

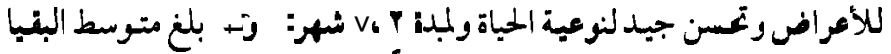

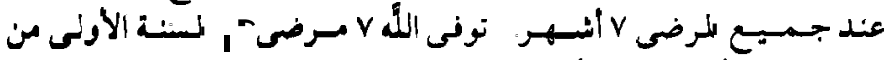

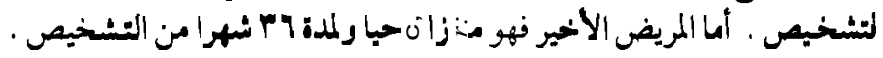

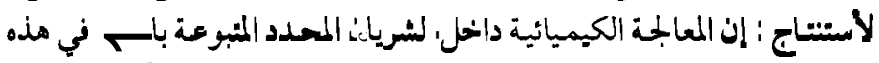

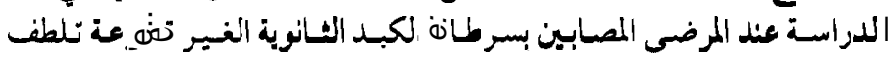

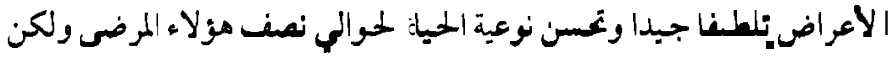

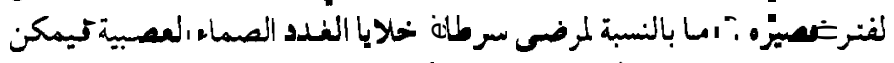

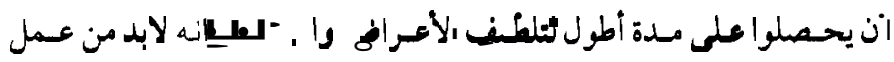

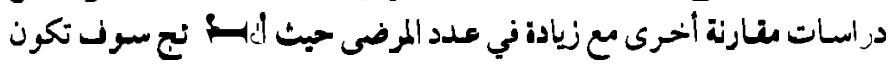

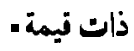

